\title{
Interaction between ROS and p38MAPK contributes to chemical hypoxia-induced injuries in PC12 cells
}

\author{
AI-PING LAN ${ }^{1}$, LIANG-CAN XIAO ${ }^{2}$, ZHAN-LI YANG $^{1}$, CHUN-TAO YANG $^{1}$, \\ XIU-YU WANG ${ }^{1}$, PEI-XI CHEN ${ }^{1}$, MO-FA GU $^{3}$ and JIAN-QIANG FENG ${ }^{1}$ \\ ${ }^{1}$ Department of Physiology, Zhongshan School of Medicine; ${ }^{2}$ Department of Anesthesiology, The First Affiliated Hospital; \\ ${ }^{3}$ Department of Radiotherapy, The Affiliated Cancer Hospital, Sun Yat-Sen University, Guangzhou 510080, P.R. China
}

Received July 3, 2011; Accepted September 28, 2011

DOI: $10.3892 / \mathrm{mmr} .2011 .623$

\begin{abstract}
The present study investigated whether there is an interaction between reactive oxygen species (ROS) and p38 mitogen-activated protein kinase (MAPK) during chemical hypoxia-induced injury in PC12 cells. The results of the present study showed that cobalt chloride $\left(\mathrm{CoCl}_{2}\right)$, a chemical hypoxia agent, markedly induced ROS generation and phosphorylation of p38MAPK, as well as neuronal injuries. $\mathrm{N}$-acetylcysteine (NAC), a ROS scavenger, blocked $\mathrm{CoCl}_{2}$-induced phosphorylation of p38MAPK. In addition, SB203580, an inhibitor of p38MAPK attenuated not only $\mathrm{CoCl}_{2}$-induced activation of p38MAPK, but also ROS production. These results suggest that ROS and p38MAPK are capable of interacting positively during chemical hypoxia. Furthermore, NAC and SB203580 markedly prevented $\mathrm{CoCl}_{2}$-induced cytotoxicity, apoptosis and a loss of mitochondrial membrane potential. Taken together, our findings suggest that the positive interaction between $\mathrm{CoCl}_{2}$ induction of ROS and $\mathrm{p} 38 \mathrm{MAPK}$ activation may play a significant role in $\mathrm{CoCl}_{2}$-induced neuronal injuries. We provide new insights into the mechanisms responsible for $\mathrm{CoCl}_{2}$-induced injuries in PC12 cells.
\end{abstract}

\section{Introduction}

Hypoxia-induced cell insult is a major concern in a variety of clinical entities, for example, ischemic disease, organ transplantation, and other diseases. Cobalt chloride $\left(\mathrm{CoCl}_{2}\right)$

Correspondence to: Professor Jian-Qiang Feng, Department of Physiology, Zhongshan School of Medicine, Sun Yat-Sen University, 74 Zhongshan 2nd Road, Guangzhou, Guangdong 510080, P.R. China

E-mail: fengjq-sums@163.com

Professor Mo-Fa Gu, Department of Radiotherapy, The Affiliated Cancer Hospital, Sun Yat-sen University, Guangzhou, Guangdong 510080, P.R. China

E-mail: lanaipingnihao@163.com

Key words: reactive oxygen species, p38 mitogen-activated protein kinase, chemical hypoxia, PC12 cells, cobalt chloride is a well-known hypoxia mimetic agent. There are numerous reports that $\mathrm{CoCl}_{2}$ mimics the hypoxia response in a number of aspects in various cultured cells, including production of reactive oxygen species (ROS), a loss of mitochondrial membrane potential (MMP), activation of hypoxia inducible factor $1 \alpha(\mathrm{HIF}-1 \alpha)$ and the expression of a number of genes, such as erythropoietin (EPO), vascular endothelial growth factor (VEGF) and endothelin-2 (ET-2)/vasoactive intestinal contractor (one of the hypoxia-related factors) (1-8). Therefore, PC12 cells (a cell line derived from rat pheochromocytoma) exposed to $\mathrm{CoCl}_{2}$ have been used to investigate events and mechanisms underlying neuronal cell death under conditions of hypoxia/ischemia $(4,6,9)$.

Accumulating evidence suggests that one of the mechanisms of $\mathrm{CoCl}_{2}$-induced neuronal damage is associated with its production of $\operatorname{ROS}(4,6,9)$. Elevated ROS is capable of attacking nucleic acids, proteins and membrane phospholipids, leading to neuronal apoptosis (10-12). Additionally, Zou et al reported that $\mathrm{CoCl}_{2}$ activates caspase-3 and p38 mitogen-activated protein kinase (MAPK), which are involved in $\mathrm{CoCl}_{2}$-induced apoptosis in PC12 cells (4). p38MAPK has been demonstrated to be one of the apoptotic markers during PC12 cell death induced by various stimuli (15-18). Notably, excessive ROS have been shown to activate members of MAPKs, including extracellular signal-regulated kinase 1/2 (ERK1/2), c-Jun-N-terminal kinase (JNK) and p38MAPK in various types of cells (19-21). Recently, studies have found that $\mathrm{H}_{2} \mathrm{O}_{2}$ induction of ROS inhibits serine/threonine protein phosphatase 2A (PP2A), a major negative regulator of phosphorylated (p)-ERK1/2, JNK and p38MAPK $(22,23)$ and protein phosphatase 5 (PP5), a negative regulator of the JNK cascade involved in stress responses $(24,25)$, leading to activation of the ERK1/2, JNK and p38MAPK pathways, thereby resulting in neuronal apoptosis (18). These findings suggest that ROS are involved in the activation of MAPK pathways. However, whether $\mathrm{CoCl}_{2}$-induced activation of p38MAPK regulates $\mathrm{CoCl}_{2}$ induction of ROS is unclear.

With this background, we investigated whether there is an interaction between $\mathrm{CoCl}_{2}$-induced $\mathrm{ROS}$ and the activation of p38MAPK, in particular, the effect of p38MAPK activation by $\mathrm{CoCl}_{2}$ on ROS production during $\mathrm{CoCl}_{2}$-induced neuronal injuries, and attempted to gain new insights into the mechanisms behind $\mathrm{CoCl}_{2}$-induced injuries in $\mathrm{PC} 12$ 
cells. Here we showed that: i) $\mathrm{CoCl}_{2}$ induced ROS production which enhanced p38MAPK activation induced by $\mathrm{CoCl}_{2}$; ii) SB203580, an inhibitor of p38MAPK, inhibited not only $\mathrm{CoCl}_{2}$-induced phosphorylation of p38MAPK, but also ROS production; and iii) NAC, a ROS scavenger, and SB203580 protected $\mathrm{PC} 12$ cells against $\mathrm{CoCl}_{2}$-induced injuries evidenced by an increase in cell viability and a decrease in apoptotic cells as well as a loss of MMP. The findings of the present study suggest that a positive interaction between $\mathrm{CoCl}_{2}$ induction of ROS and activation of the p38MAPK may exist in the $\mathrm{CoCl}_{2}$-induced neuronal injury process, which may be one of the key mechanisms responsible for $\mathrm{CoCl}_{2}-$ induced injuries in PC12 cells.

\section{Materials and methods}

Materials. Sodium hydrogen sulfide (NaHS), SB203580, $\mathrm{CoCl}_{2}$, N-acetyl-L-cysteine (NAC), dichlorofluorescein diacetate (DCFH-DA) and Rhodamine 123 (Rh123) were purchased from Sigma-Aldrich (St. Louis, MO, USA). The Cell Counter kit-8 (CCK-8) was purchased from Dojindo Lab (Japan). DMEM medium and fetal bovine serum (FBS) were supplied by Gibco BRL (Grand Island, NY, USA). p-p38 and p38 antibody were purchased from Cell Signaling Technology (Boston, MA, USA). HRP-conjugated secondary antibody and BCA protein assay kit were purchased from Kangchen Bio-Tech (Shanghai, China). ECL solution was supplied by KeyGen Biotech (Nanjing, China).

Cell culture and treatments. Rat pheochromocytoma PC12 cells were obtained from Sun Yat-sen University Experimental Animal Centre (Guangzhou, China) and were grown in DMEM medium supplemented with $10 \% \mathrm{FBS}$ at $37^{\circ} \mathrm{C}$ under an atmosphere of $5 \% \mathrm{CO}_{2}$ and $95 \%$ air.

Cell viability assay. Cell viability was detected by using the CCK-8 kit. PC12 cells were cultured in 96-well plates, with 4 duplicate wells in each group. When $70-80 \%$ confluence was reached, the cells were treated with conditioned media as indicated. Following the indicated treatments, $10 \mu \mathrm{l} \mathrm{CCK}-8$ solution was added into each well and then the plates were incubated for $3 \mathrm{~h}$ in the incubator. Absorbance at $450 \mathrm{~nm}$ was measured with a microplate reader (Molecular Devices, Sunnyvale, CA, USA). The means of the optical density (OD) measurements from 4 wells of the indicated groups were used to calculate the percentage of cell viability according to the formula: Percentage of cell viability $=(\mathrm{OD}$ treatment group $/$ OD control group) x $100 \%$. The experiment was repeated three times.

Nuclear staining for assessment of apoptosis. Chromosomal condensation and morphological changes in the nuclei of PC12 cells were observed with the chromatin dye Hoechst 33258 followed by photofluorography. The cells were fixed with $4 \%$ paraformaldehyde in phosphate-buffered saline (PBS) for $10 \mathrm{~min}$. After three washes with PBS, cells were stained with $5 \mathrm{mg} / \mathrm{l}$ Hoechst 33258 for $10 \mathrm{~min}$, and then washed briefly with PBS and air-dried again. The cells were visualized under a fluorescence microscope (BX50-FLA, Olympus). Viable cells displayed normal nuclear size and uniform fluorescence, whereas apoptotic cells showed condensed, fractured or distorted nuclei.

Measurement of intracellular ROS generation. Intracellular ROS content was determined by 2',7'-dichlorofluorescin (DCF) staining followed by photofluorography. DCF is a fluorescent substance derived from cell-permeable DCFH-DA (Sigma-Aldrich). PC12 cells were cultured on a slide in DMEM. DCFH-DA in FBS-free DMEM was added at a final concentration of $10 \mu \mathrm{mol} / 1$ to the PC12 cells. Cells were then incubated at $37^{\circ} \mathrm{C}$ for $60 \mathrm{~min}$ and the indicated treatments were performed. After all the treatments were accomplished, slides were washed three times with FBS-free DMEM, and DCF-fluorescence was measured over the entire field of vision with a fluorescent microscope connected to an imaging system (BX50-FLA; Olympus, Tokyo). Mean fluorescence intensity (MFI) (which represents the amount of intracellular ROS content) from 3 random fields was analyzed using ImageJ 1.41o software (National Institute of Health, Bethesda, MD, USA).

Measurement of MMP. MMP was monitored by using a fluorescent dye, Rh123, a cell-permeable cationic dye that preferentially enters into mitochondria based on the highly negative MMP. Depolarization of MMP results in a loss of Rh123 from mitochondria and a decrease in intracellular green fluorescence. In the present study, Rh123 (100 mg/l) was added into cell cultures for $60 \mathrm{~min}$ at $37^{\circ} \mathrm{C}$ and fluorescence was measured over the entire field of vision by using a fluorescence microscope connected to the imaging system. The MFI of Rh123 from 4 random fields was analyzed using the ImageJ 1.41o software and the MFI was taken as an index of the level of MMP.

Western blot analysis for protein expression. PC12 cells were plated in 35-mm diameter Petri dishes. When grown to 70-80\% confluence, the cells were treated as indicated. At the end of the treatments, PC12 cells were harvested and resuspended in ice-cold cell lysis solution and the homogenate was centrifuged at $10,000 \mathrm{x}$ for $15 \mathrm{~min}$ at $4^{\circ} \mathrm{C}$. Total protein in the supernatant was measured using a bicinchoninic acid (BCA) protein assay kit (Kangchen BioTech, Shanghai, China). Total protein $(30 \mu \mathrm{g})$ from each sample was separated by $12 \%$ SDS-PAGE. The protein in the gel was transferred onto a polyvinylidene difluoride (PVDF) membrane. The membrane was blocked with 5\% fat-free dry milk in TBST for $1 \mathrm{~h}$ at room temperature, and then incubated with the primary antibody specific to p-p38, p38 (Cell Signaling Technology, Beverly, MA, USA) overnight with gentle agitation at $4^{\circ} \mathrm{C}$. The next day, the membrane was washed and subsequently incubated with HRP-conjugated secondary antibodies for $1.5 \mathrm{~h}$ at room temperature. Following three washes with TBST, the membranes were developed using an enhanced chemiluminescence kit (Applygen Technologies, Beijing, China) and exposed to X-ray films. ImageJ 1.41 o software was used to quantitatively analyze the protein expression level. The experiment was carried out in triplicate with similar results.

Statistical analysis. All data are presented as the mean \pm SEM. The assessment of differences between groups was analyzed 

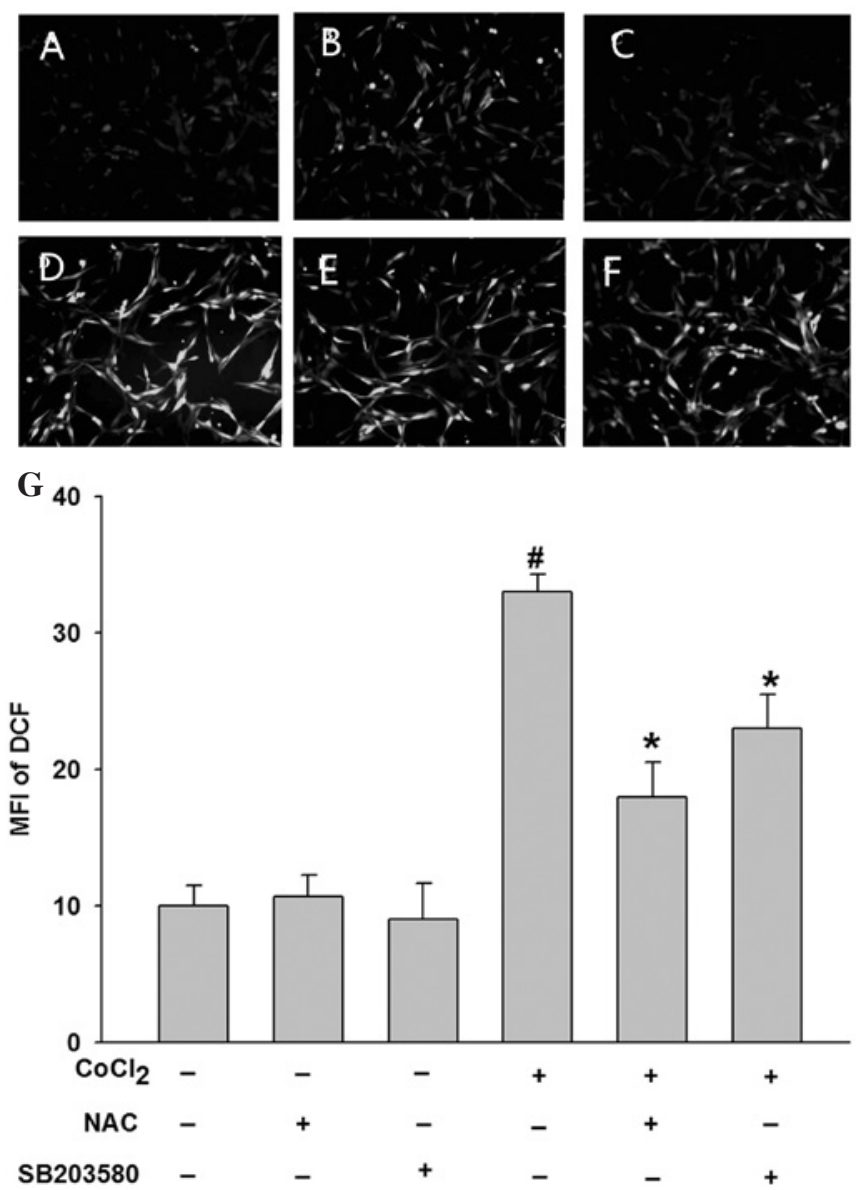

Figure 1. Effects of NAC and $\mathrm{SB} 203580$ on $\mathrm{CoCl}_{2}$-induced ROS production in PC12 cells. (A-F) DCFH-DA staining followed by photofluorography to observe the intracellular ROS in PC12 cells. (A) Control group. (B) PC12 cells exposed to $500 \mu \mathrm{mol} / 1 \mathrm{NAC}$ for $60 \mathrm{~min}$ followed by a 6 -h culture. (C) PC12 cells were treated with $20 \mu \mathrm{mol} / 1 \mathrm{SB} 203580$, an inhibitor of p38MAPK, for 60 min followed by a 6 -h culture. (D) PC12 cells subjected to $600 \mu \mathrm{mol} / 1 \mathrm{CoCl}_{2}$ treatment for $6 \mathrm{~h}$. (E) $\mathrm{PC} 12$ cells were pretreated with $500 \mu \mathrm{mol} / 1 \mathrm{NAC}$ for $60 \mathrm{~min}$ prior to exposure to $\mathrm{CoCl}_{2}$. (F) PC12 cells were preconditioned with $20 \mu \mathrm{mol} / 1 \mathrm{SB} 203580$ for $60 \mathrm{~min}$ followed by $\mathrm{CoCl}_{2}$ treatment. (G) Quantitative analysis of the mean fluorecence intensity (MFI) of DCF with ImageJ 1.41 o software. ${ }^{*} \mathrm{P}<0.01$ vs. the control group; ${ }^{*} \mathrm{P}<0.01$ vs. the $600 \mu \mathrm{mol} / 1 \mathrm{CoCl}_{2}$ group.

by one-way ANOVA with SPSS 13.0 (SPSS Inc.). P<0.05 was considered to be statistically significant.

\section{Results}

NAC attenuates $\mathrm{CoCl}_{2}$-induced ROS and neuronal injuries. Exposure of PC12 cells to $600 \mu \mathrm{mol} / 1 \mathrm{CoCl}_{2}$ for $6 \mathrm{~h}$ led to a significant increase in DCF-derived fluorescence, manifesting an accumulation of intracellular ROS (Fig. 1D and G). Further study showed that $\mathrm{CoCl}_{2}$-induced $\mathrm{ROS}$ production was markedly decreased by pretreatment with $500 \mu \mathrm{mol} / 1$ NAC, a ROS scavenger, for $60 \mathrm{~min}$ (Fig. 1E and G). Moreover, our findings showed that treatment of cells with $600 \mu \mathrm{mol} / 1$ $\mathrm{CoCl}_{2}$ for $24 \mathrm{~h}$ markedly reduced cell viability and that NAC at $500 \mu \mathrm{mol} / 1$ significantly suppressed this inhibitory effect of $\mathrm{CoCl}_{2}$ (Fig. 2H). In addition, exposure of PC12 cells to $600 \mu \mathrm{mol} / 1 \mathrm{CoCl}_{2}$ for $48 \mathrm{~h}$ caused a marked increase in the percentage of apoptotic cells (Fig. $2 \mathrm{D}$ and $\mathrm{G}$ ). $\mathrm{CoCl}_{2}$-induced apoptosis was considerably depressed by pretreatment with
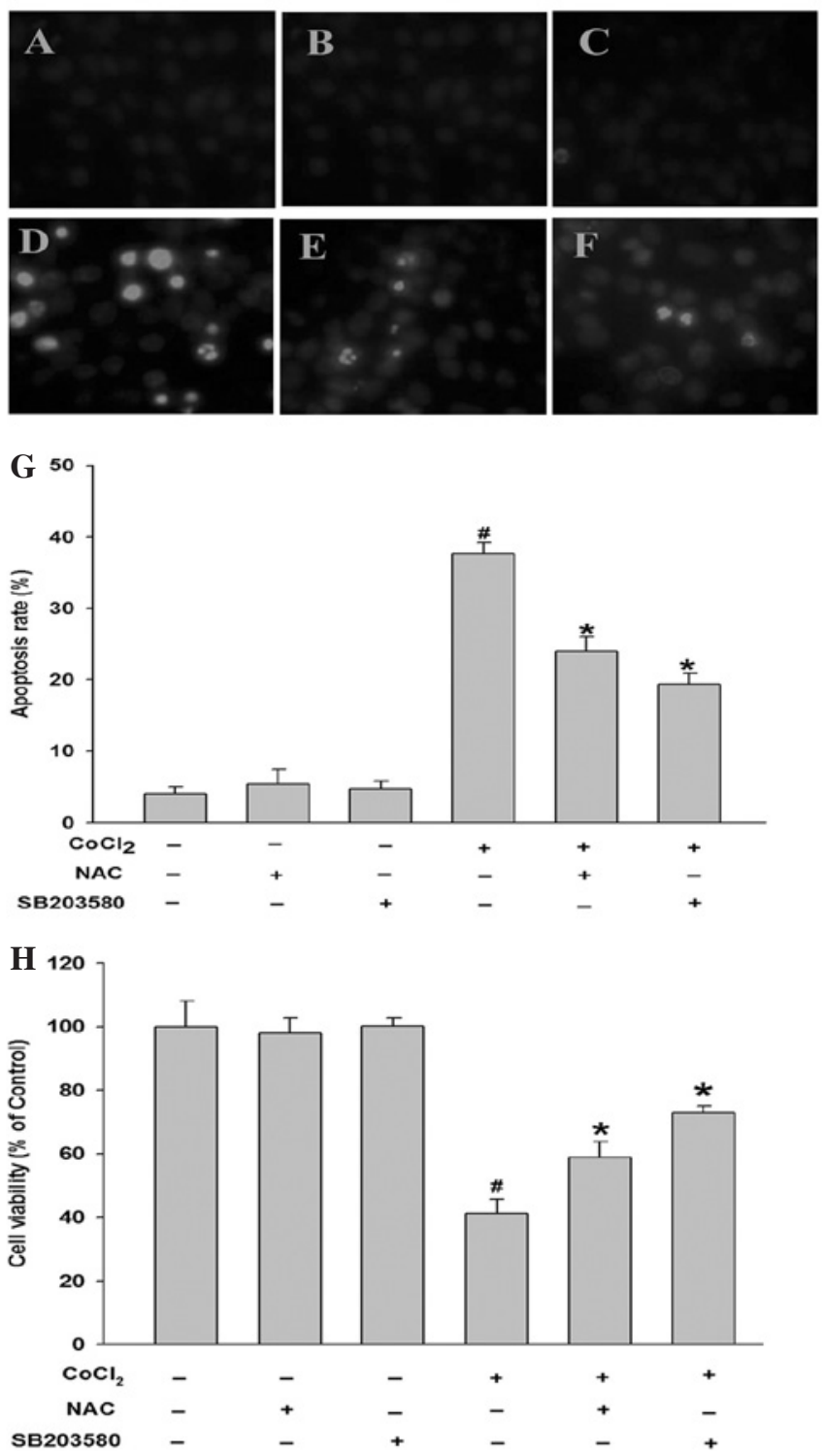

Figure 2. Protection of NAC and SB203580 against $\mathrm{CoCl}_{2}$-induced apoptosis and cytotoxicity in PC12 cells. (A-F) Hoechst 33258 nuclear staining followed by photofluorography to observe cellular apoptosis. (A) Control group. (B) PC12 cells were treated with $500 \mu \mathrm{mol} / 1 \mathrm{NAC}$ for $60 \mathrm{~min}$ followed by a 48-h culture. (C) PC12 cells were exposed to $20 \mu \mathrm{mol} / 1 \mathrm{SB} 203580$ for $60 \mathrm{~min}$ followed by culture for $48 \mathrm{~h}$. (D) PC12 cells were treated with $600 \mu \mathrm{mol} / 1$ $\mathrm{CoCl}_{2}$ for $48 \mathrm{~h}$. (E) PC12 cells were pretreated with $500 \mu \mathrm{mol} / 1 \mathrm{NAC}$ for 60 min prior to exposure to $\mathrm{CoCl}_{2}$ for $48 \mathrm{~h}$. (F) PC12 cells were pretreated with $20 \mu \mathrm{mol} / 1 \mathrm{SB} 203580$ for $60 \mathrm{~min}$ prior to $\mathrm{CoCl}_{2}$ treatment. (G) The apoptotic rate was analyzed with a cell counter from the ImageJ $1.41 \mathrm{o}$ software. ${ }^{~} \mathrm{P}<0.01$ vs. the control group; ${ }^{*} \mathrm{P}<0.01$ vs. the $600 \mu \mathrm{mol} / 1 \mathrm{CoCl}_{2}$ group. (H) PC12 cells were treated with $600 \mu \mathrm{mol} / 1 \mathrm{CoCl}_{2}$ for $24 \mathrm{~h}$ in the presence or absence of pretreatment with NAC or pretreatment with SB203580. The CCK-8 assay was performed to measure cell viability. ${ }^{\#} \mathrm{P}<0.01$ vs. the control group. " $\mathrm{P}<0.01$ vs. the $600 \mu \mathrm{mol} / 1 \mathrm{CoCl}_{2}$ group.

$500 \mu \mathrm{mol} / 1 \mathrm{NAC}$ for $60 \mathrm{~min}$ (Fig. 2E and G). Furthermore, the results of the Rh123 staining assay indicated that after PC12 cells were subjected to $600 \mu \mathrm{mol} / 1 \mathrm{CoCl}_{2}$ for $24 \mathrm{~h}$, mitochondria were dramatically damaged, resulting in a decrease in the uptake of Rh123, indicating dissipation of MMP (Fig. 3D and $\mathrm{G})$. The loss of MMP was ameliorated by pretreatment with $500 \mu \mathrm{mol} / 1 \mathrm{NAC}$ for $60 \mathrm{~min}$ (Fig. 3E and G). NAC at $500 \mu \mathrm{mol} / 1$ alone did not alter ROS production, cell viability, apoptosis or MMP, respectively (Figs. 1-3). 

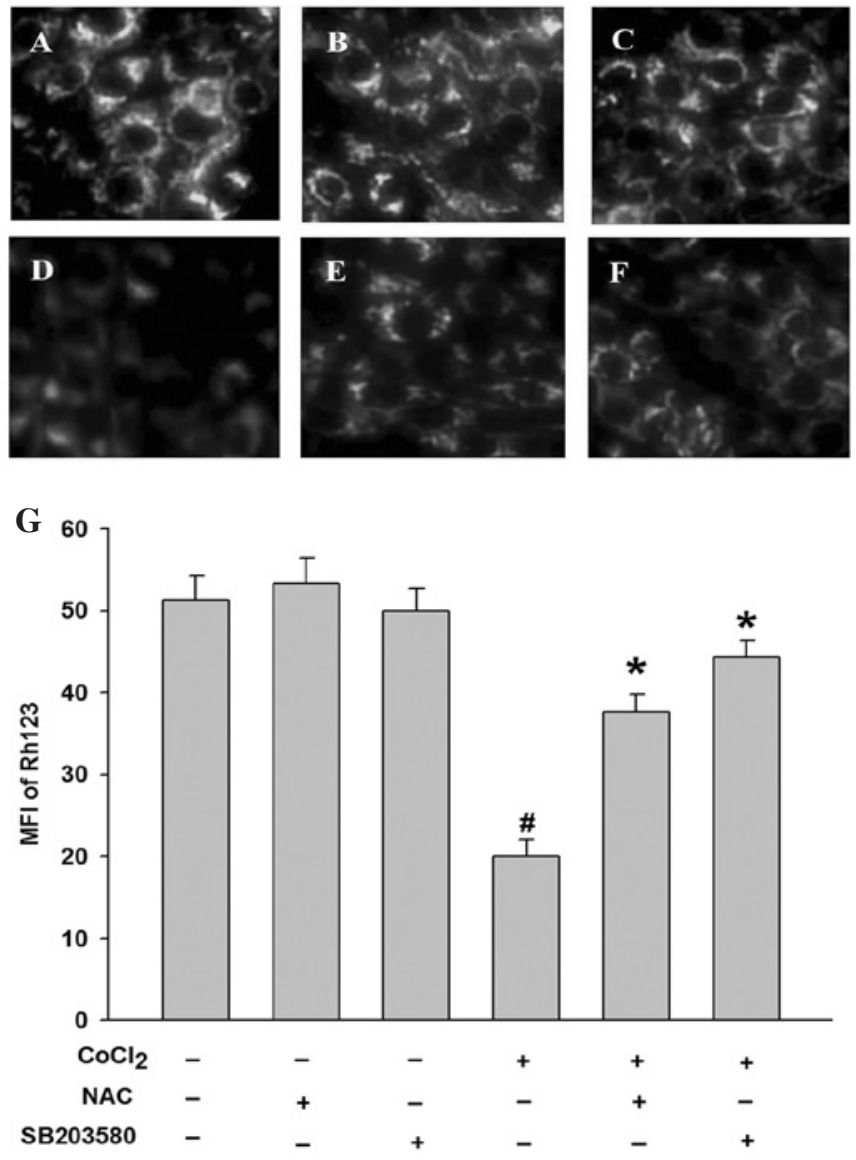

Figure 3. Protection of NAC and SB203580 against $\mathrm{CoCl}_{2}$-induced loss of MMP in PC12 cells. (A-F) Rh123 staining following by photofluorography to measure mitochondrial membrane potential (MMP). (A) Control group (B) PC12 cells were treated with $500 \mu \mathrm{mol} / 1 \mathrm{NAC}$ for $60 \mathrm{~min}$ followed by a 24-h culture. (C) PC12 cells were treated with $20 \mu \mathrm{mol} / 1 \mathrm{SB} 203580$ for $60 \mathrm{~min}$ followed by a 24-h culture. (D) PC12 cells were treated with $600 \mu \mathrm{mol} / 1 \mathrm{CoCl}_{2}$ for $24 \mathrm{~h}$. (E) PC12 cells were pretreated with $500 \mu \mathrm{mol} / 1$ $\mathrm{NAC}$ for $60 \mathrm{~min}$ prior to $\mathrm{CoCl}_{2}$ treatment. (F) PC12 cells were pretreated with SB203580 for 60 min prior to $\mathrm{CoCl}_{2}$ treatment. $(\mathrm{H})$ Quantitative analysis of MFI of Rh123 in A-F with the ImageJ 1.41 o software. ${ }^{\#} \mathrm{P}<0.01$ vs. the control group; ${ }^{*} \mathrm{P}<0.01$ vs. the $600 \mu \mathrm{mol} / 1 \mathrm{CoCl}_{2}$ group.

p38MAPK is involved in $\mathrm{CoCl}_{2}$-induced neuronal injuries. As shown in Fig. 4A and B, after PC12 cells were exposed to $600 \mu \mathrm{mol} / 1 \mathrm{CoCl}_{2}$ for $2 \mathrm{~h}$, the expression of p-p38MAPK was increased 4.7 -fold compared with the control group $(\mathrm{P}<0.01)$. However, the expression of total p38MAPK was not altered. Further study revealed that pretreatment of cells with $20 \mu \mathrm{mol} / 1 \mathrm{SB} 203580$ (an inhibitor of p38MAPK) for 60 min prior to exposure to $\mathrm{CoCl}_{2}$ significantly attenuated $\mathrm{CoCl}_{2}$-induced cytotoxicity, leading to an increase in cell viability $(72.16 \pm 2.3 \%)(\mathrm{P}<0.01)$, whereas SB203580 alone had no effect on cell viability in PC12 cells (Fig. 2H). Additionally, pretreatment with SB203580 also blocked $\mathrm{CoCl}_{2}$-induced apoptosis (Fig. 2F and G) and dissipation of MMP (Fig. 3F and G). These results suggest that $\mathrm{CoCl}_{2}$ is capable of activating the p38MAPK pathway, which mediates neuronal injuries induced by $\mathrm{CoCl}_{2}$.

$\mathrm{CoCl}_{2}$-induced ROS activates the p38MAPK pathway in $\mathrm{PC} 12$ cells. Since $\mathrm{CoCl}_{2}$-induced neuronal injuries are attributed to its induction of ROS and p38MAPK activation (Figs. 2 and
3 ), we further investigated whether $\mathrm{CoCl}_{2}$-induced activation of p38MAPK is due to its induction of ROS. As shown in Fig. $4 \mathrm{C}$ and D, pretreatment of cells with $500 \mu \mathrm{mol} / 1 \mathrm{NAC}$ for $60 \mathrm{~min}$ before exposure to $\mathrm{CoCl}_{2}$ at $600 \mu \mathrm{mol} / 1$ for $2 \mathrm{~h}$ markedly inhibited $\mathrm{CoCl}_{2}$-induced phosphorylation of $\mathrm{p} 38 \mathrm{MAPK}$, whereas pretreatment with NAC had no effect on the expression of total p38MAPK (Fig. 4C and D).

$\mathrm{CoCl}_{2}$-induced activation of $\mathrm{p} 38 \mathrm{MAPK}$ promotes $\mathrm{ROS}$ production in PC12 cells. To determine the role of the p38MAPK pathway in $\mathrm{CoCl}_{2}$-induced ROS production, $\mathrm{PC} 12$ cells were pretreated with $20 \mu \mathrm{mol} / 1 \mathrm{SB} 203580$ for 60 min prior to exposure to $600 \mu \mathrm{mol} / 1 \mathrm{CoCl}_{2}$ for $6 \mathrm{~h}$, followed by DCFH-DA staining and photofluorography to observe the intracellular ROS. As shown in Fig. 1, pretreatment with SB203580 led to a decrease in DCF-derived fluorescence, exhibiting a decrease in intracellular ROS (Fig. 1F and G). These findings suggest that the p38MAPK pathway is involved in $\mathrm{CoCl}_{2}$-induced ROS production.

\section{Discussion}

It is widely accepted that oxidative stress is associated with hypoxia/ischemia-linked neuronal cell death, which is involved in a number of neurogenerative disorders, such as Parkinson's disease, Alzheimer's disease and amyotrophic lateral sclerosis (26-29). Under oxidative stress, ROS, including free radicals such as superoxide $\left(\mathrm{O}_{2}^{-}\right)$, hydroxyl radical $\left(\mathrm{HO}^{-}\right)$and $\mathrm{H}_{2} \mathrm{O}_{2}$, are generated at high levels $(12,30)$. Excessive amounts of ROS induced by oxidative stress may modify protein, lipids and DNA and alter their functions, resulting in apoptosis of neuronal cells $(19,31)$. Our previous study and other studies (6) have demonstrated that $\mathrm{CoCl}_{2}$ elicits oxidative stress, which contributes to neuronal apoptosis. In agreement with the previous studies (6), our results showed that $\mathrm{CoCl}_{2}$ induced ROS generation, which mediated $\mathrm{CoCl}_{2}$-induced neuronal injuries, including cytotoxicity, mitochondrial damage and apoptosis. This is supported by the following results: i) $\mathrm{CoCl}_{2}$-induced cytotoxicity was prevented by NAC, a ROS scavenger; ii) NAC blocked a loss of MMP induced by $\mathrm{CoCl}_{2}$; iii) NAC attenuated $\mathrm{CoCl}_{2}$-induced apoptosis.

p38MAPK is a distinct member of the MAPK family. In neuronal cells, the p38 signaling pathway is preferentially activated by inflammatory cytokines and environmental stress, such as osmotic stress, ultraviolet light, heat shock and hypoxia. It can also be activated by ROS $(12,18-21)$. Previous studies have demonstrated that p38MAPK activation is implicated in neuronal damage associated with ischemia and neurodegenerative disease (32), and it is one of the apoptotic markers during PC12 cell death induced by a variety of stimuli (15-18). In the present study, we found that exposure of $\mathrm{PC} 12$ cells to $\mathrm{CoCl}_{2}$ significantly upregulated expression of p-p38MAPK and that pretreatment of cells with SB203580, an inhibitor of p38MAPK, markedly blocked $\mathrm{CoCl}_{2}$-induced neuronal injuries, indicating that activation of p38MAPK mediates neuronal damage induced by $\mathrm{CoCl}_{2}$. Our results are consistent with the results reported by Zou et al (4) and are comparable with the evidence that $\mathrm{H}_{2} \mathrm{O}_{2}$-induced apoptosis of neuronal cells is associated with activation of p38MAPK (18). 

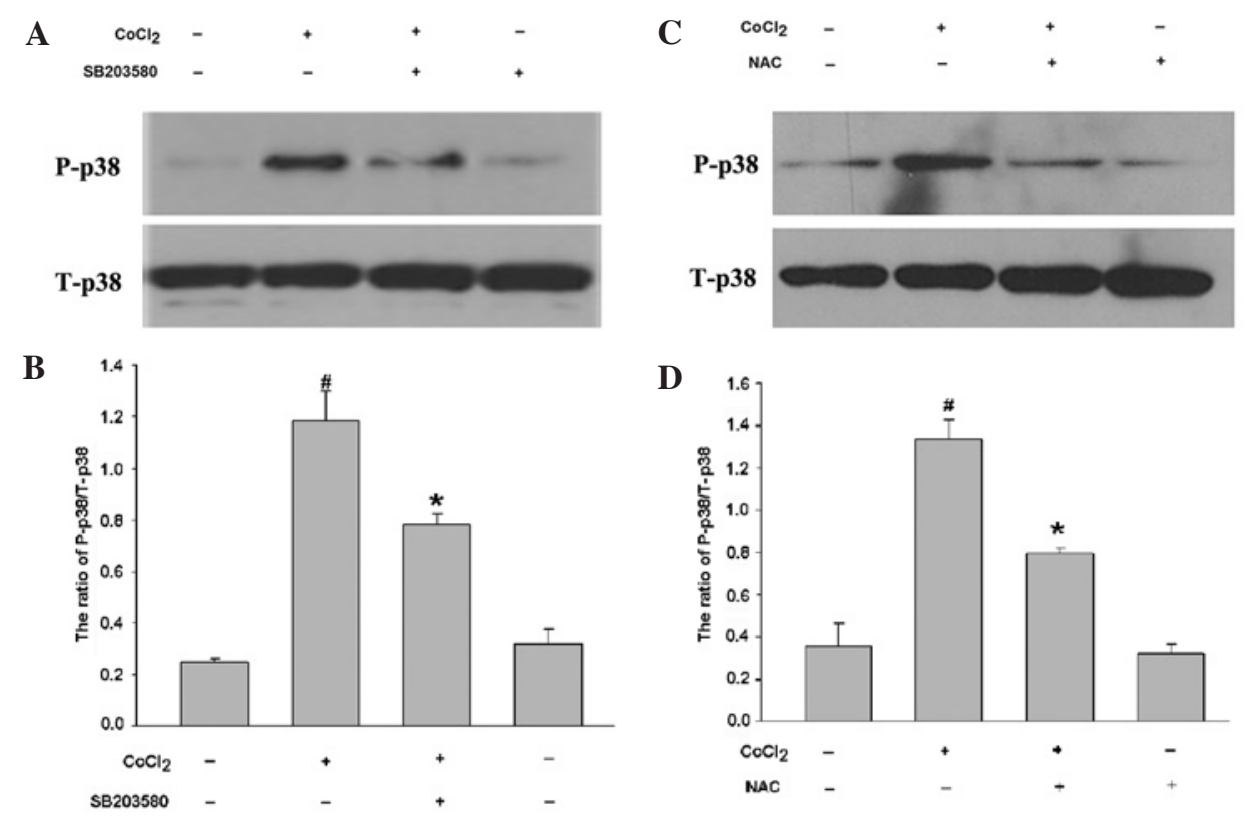

Figure 4. Inhibitory effects of SB203580 and NAC on the phosphorylation of p38MAPK induced by $\mathrm{CoCl}_{2}$ in $\mathrm{PC}_{2} 2$ cells. (A and B) PC12 cells were treated with $600 \mu \mathrm{mol} / 1 \mathrm{CoCl}_{2}$ for $2 \mathrm{~h}$ in the presence or absence of pretreatment with $20 \mu \mathrm{mol} / 1 \mathrm{SB} 203580$, an inhibitor of p38MAPK, for $60 \mathrm{~min}$. (C and D) PC12 cells were treated with $600 \mu \mathrm{mol} / 1 \mathrm{CoCl}_{2}$ for $2 \mathrm{~h}$ in the presence or absence of pretreatment with $500 \mu \mathrm{mol} / 1 \mathrm{NAC}$ for 60 min. (A and C) Expression of p38MAPK was detected by Western blot analysis and (B and D) quantified by densitometric analysis with ImageJ 1.41 software. ${ }^{\prime} \mathrm{P}<0.01$ vs. the control group; ${ }^{*} \mathrm{P}<0.01$ vs. the $600 \mu \mathrm{mol} / 1 \mathrm{CoCl}_{2}$ group.

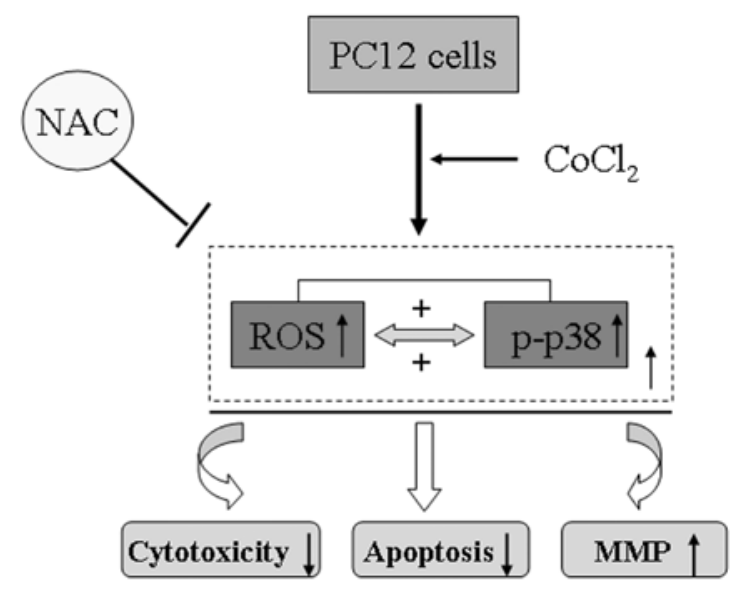

Figure 5. Proposed positive interaction between $\mathrm{CoCl}_{2}$ induction of ROS and activation of p38MAPK during $\mathrm{CoCl}_{2}$-induced injuries in PC12 cells. + , stimulation.

Notably, our studies further demonstrated that NAC, a ROS scavenger, attenuated not only $\mathrm{CoCl}_{2}$-induced ROS, but also activation of $\mathrm{p} 38 \mathrm{MAPK}$ by $\mathrm{CoCl}_{2}$, suggesting that $\mathrm{CoCl}_{2}$ induction of ROS activates the p38MAPK pathway. Our results are supported by a recent study, which showed that $\mathrm{H}_{2} \mathrm{O}_{2}$ induction of ROS contributes to p38MAPK activation (18). Collectively, the findings from our group and others (18-20) support the notion that ROS activation of the p38MAPK pathway may be a common mechanism by which oxidative stress or hypoxia/ ischemia induces neuronal cell death or neurodegenerative disorders.

Importantly, here, for the first time, we showed that $\mathrm{CoCl}_{2}$-induced activation of $\mathrm{p} 38 \mathrm{MAPK}$ is capable of regulating ROS overproduction induced by $\mathrm{CoCl}_{2}$ in $\mathrm{PC} 12$ cells. After PC12 cells were pretreated with SB203580 prior to exposure to $\mathrm{CoCl}_{2}, \mathrm{CoCl}_{2}$-induced ROS production was markedly blocked, suggesting that p38MAPK may be a positive regulator for $\mathrm{CoCl}_{2}$-induced ROS production in PC12 cells. Previous studies reported that ROS appeared to be upstream of p38MAPK (33). However, based on our results, ROS and p38MAPK may locate at a parallel level, and there is interaction between ROS and p38MAPK during $\mathrm{CoCl}_{2}$-induced neuronal injuries.

In conclusion, the present study provided novel evidence that $\mathrm{CoCl}_{2}$ induction of ROS activates the p38MAPK pathway which is involved in $\mathrm{CoCl}_{2}$-induced neuronal injuries and that $\mathrm{CoCl}_{2}$-induced activation of p38MAPK also promotes ROS production induced by $\mathrm{CoCl}_{2}$. The positive interaction between $\mathrm{CoCl}_{2}$ induction of ROS and activation of p38MAPK may play a significant role in $\mathrm{CoCl}_{2}$-induced neuronal injuries (Fig. 5). However, further studies are required to elucidate the molecular mechanisms responsible for the interaction between ROS induction and p38MAPK activation during $\mathrm{CoCl}_{2}-$ induced injuries in PC12 cells.

\section{Acknowledgements}

This study was supported by the Science and Technology Planning Project of Guangzhou Province, China (2010B080701035, 2008B080703053).

\section{References}

1. Chandel NS, Maltepe E, Goldwasser E, et al: Mitochondrial reactive oxygen species trigger hypoxia-induced transcription. Proc Natl Acad Sci USA 95: 11715-11720, 1998.

2. Guillemin K and Krasnow MA: The hypoxic response: huffing and HIFing. Cell 89: 9-12, 1997.

3. Yang SJ, Pyen J, Lee I, et al: Cobalt chloride-induced apoptosis and extracellular signal-regulated protein kinase $1 / 2$ activation in rat C6 glioma cells. Biochem Mol Biol 37: 480-486, 2004. 
4. Zou W, Zeng J, Zhuo M, et al: Involvement of caspase-3 and p38mitogen-activated protein kinase in cobalt choride-induced apoptosis in PC12 cells. J Neurosci Res 67: 837-843, 2002.

5. Kotake-Nara E and Saida K: Characterization of $\mathrm{CoCl}_{2}$-induced reactive oxygen species (ROS): Inductions of neutrite outgrowth and endothelin-2/vasoactive intestinal contractor in PC12 cells by $\mathrm{CoCl}_{2}$ are ROS dependent, but those by $\mathrm{MnCl}_{2}$ are not Neurosci Lett 422: 223-227, 2007.

6. Chen JX, Zhao T and Huang DX: Protective effects of edaravone against cobalt chloride-induced apoptosis in PC12 cells Neurosci Bull 25: 67-74, 2009.

7. Chen SL, Yang CT and Yang ZL, et al: Hydrogen sulphide protects $\mathrm{H} 9 \mathrm{c} 2$ cells against chemical hypoxia-induced injury. Clin Exp Pharmacol Physiol 37: 316-321, 2010.

8. Yang Z, Yang C and Xiao L, et al: Novel insights into the role of HSP90 in cytoprotection of $\mathrm{H}_{2} \mathrm{~S}$ against chemical hypoxiainduced injury in $\mathrm{H} 9 \mathrm{c} 2$ cardiac myocytes. Int $\mathrm{J}$ Mol Med 28 397-403, 2011.

9. Jung JY, Roh KH and Jeong YJ, et al: Estradiol protects PC12 cells against $\mathrm{CoCl}_{2}$-induced apoptosis. Brain Res Bull 76 579-585, 2008.

10. Wang G, Hazra TK, Mitra S, et al: Mitochondrial DNA damage and a hypoxic response are induced by $\mathrm{CoCl}_{2}$ in rat neuronal PC12 cells. Nucleic Acids Res 28: 2135-2140, 2000.

11. Cao YJ, Shibata T and Rainov NG: Hypoxia-inducible transgene expression in differentiated human NT2N neurons - a cell culture model for gene therapy of postischemic neuronal loss. Gene Ther 8: 1357-1362, 2001.

12. Chen L, Liu L and Huang S: Cadmium activates the mitogenactivated protein kinase (MAPK) pathway via induction of reactive oxygen species and inhibition of protein phosphatases $2 \mathrm{~A}$ and 5. Free Radic Biol Med 45: 1035-1044, 2008.

13. Xia Z, Dickens M, Raingeaud J, Davis RJ and Greenberg ME: Opposing effects of ERK and JNK-p38 MAP kinases on apoptosis. Science 270: 1326-1331, 1995.

14. Roth JA, Feng L, Walowitz J and Browne RW: Manganese-induced rat pheochromocytoma (PC12) cell death is independent of caspase activation. J Neurosci Res 61: 162-171, 2000.

15. Han OJ, Joe KH, Kim SW, et al: Involvement of p38 mitogenactivated protein kinase and apoptosis signal-regulating kinase- 1 in nitric oxide-induced cell death in PC12 cells. Neurochem Res 26: 525-532, 2001.

16. Lee SY, Lee JW, Lee H, et al: Inhibitory effect of green tea extract on beta-amyloid-induced $\mathrm{PC} 12$ cell death by inhibition of the activation of NF-kappaB and ERK/p38 MAP kinase pathway through antioxidant mechanisms. Mol Brain Res 140: 45-54, 2005 .

17. Nusuetrong P, Yoshida M, Tanitsu MA, et al: Involvement of reactive oxygen species and stress-activated MAPKs in satratoxin H-induced apoptosis. Eur J Pharmacol 507: 239-246, 2005.

18. Chen L, Liu L, Yin J, Luo Y and Huang S: Hydrogen peroxide-induced neuronal apoptosis is associated with inhibition of protein phosphatase $2 \mathrm{~A}$ and 5 , leading to activation of MAPK pathway. Int J Biochem Cell Biol 41: 1284-1295, 2009.
19. Kim SD, Moon CK, Eun SY, Ryu PD and Jo SA: Identification of ASK1, MKK4, JNK, c-Jun, and caspase-3 as a signaling cascade involved in cadmium-induced neuronal cell apoptosis. Biochem Biophys Res Commun 328: 326-334, 2005.

20. Ouyang M and Shen X: Critical role of ASK1 in the 6-hydroxydopamine-induced apoptosis in human neuroblastoma SH-SY5Y cells. J Neurochem 97: 234-244, 2006.

21. Yeo JE, Kim JH and Kang SK: Selenium attenuates ROS-mediated apoptotic cell death of injured spinal cord through prevention of mitochondria dysfunction; in vitro and in vivo study. Cell Physiol Biochem 21: 225-238, 2008.

22. Liu Y, Shepherd EG and Nelin LD: MAPK phosphatases regulating the immune response. Nat Rev Immunol 7: 202-212, 2007.

23. Van Kanegan MJ, Adams DG, Wadzinski BE and Strack S: Distinct protein phosphatase 2A heterotrimers modulate growth factor signaling to extracellular signal-regulated kinases and Akt. J Biol Chem 280: 36029-36036, 2005.

24. Huang S, Shu L, Easton J, et al: Inhibition of mammalian target of rapamycin activates apoptosis signal-regulating kinase 1 signaling by suppressing protein phosphatase 5 activity. J Biol Chem 279: 36490-36496, 2004.

25. Morita K, Saitoh M, Tobiume K, et al: Negative feedback regulation of ASK1 by protein phosphatase 5 (PP5) in response to oxidative stress. EMBO J 20: 6028-6036, 2001.

26. Alexi T, Borlongan CV, Faull RL, et al: Neuroprotective strategies for basal ganglia degeneration: Parkinson's and Huntington's diseases. Prog Neurobiol 60: 409-470, 2000.

27. Chen L, Liu L, Luo Y and Huang S: MAPK and mTOR pathways are involved in cadmium-induced neuronal apoptosis. J Neurochem 105: 251-261, 2008.

28. Wu DC, Ré DB, Nagai M, Ischiropoulos H and Przedborski S: The inflammatory NADPH oxidase enzyme modulates motor neuron degeneration in amyotrophic lateral sclerosis mice. Proc Natl Acad Sci USA 103: 12132-12137, 2006.

29. Ruffels J, Griffin M and Dickenson JM: Activation of ERK1/2, JNK and PKB by hydrogen peroxide in human SH-SY5Y neuroblastoma cells: role of ERK1/2 in $\mathrm{H}_{2} \mathrm{O}_{2}$-induced cell death. Eur J Pharmacol 483: 163-73, 2004

30. Valencia A and Morán J: Reactive oxygen species induce different cell death mechanisms in cultured neurons. Free Radic Biol Med 36: 1112-11125, 2004.

31. Green KN and Peers C: Divergent pathways account for two distinct effects of amyloid beta peptides on exocytosis and $\mathrm{Ca}(2+)$ currents: involvement of ROS and NF-kappaB. J Neurochem 81: 1043-1051, 2002.

32. Ghatan S, Larner S, Kinoshita Y, et al: p38 MAP kinase mediates bax translocation in nitric oxide-induced apoptosis in neurons. J Cell Biol 150: 335-347, 2000.

33. Robinson KA, Stewart CA, Pye QN, et al: Redox-sensitive protein phosphatase activity regulates the phosphorylation state of p38 protein kinase in primary astrocyte culture. J Neurosci Res 55: 724-732, 1999. 